\title{
Sociomateriality Implications of Software as a Service Adoption on IT- Workers' Roles and Changes in Organizational Routines of IT Systems Support
}

\author{
Freddie Mbuba ${ }^{1}$, William Yu Chung Wang ${ }^{1}$, Karin Olesen $^{1}$, \\ ${ }^{1}$ Faculty of Business and Law, Auckland University of Technology, New Zealand, \\ \{fmbuba, wiwang, kolesen\}@aut.ac.nz
}

\begin{abstract}
This paper aims to deepen our understanding on how sociomateriality practices influence IT workers' roles and skill set requirements and changes to the organizational routines of IT systems support, when an organization migrates an on-premise IT system to a software as a service (SaaS) model. This conceptual paper is part of an ongoing study investigating organizations that migrated on-premise IT email systems to SaaS business models, such as Google Apps for Education (GAE) and Microsoft Office 365 systems, in New Zealand tertiary institutions. We present initial findings from interpretive case studies. The findings are, firstly, technological artifacts are entangled in sociomaterial practices, which change the way humans respond to the performative aspects of the organizational routines. Human and material agencies are interwoven in ways that reinforce or change existing routines. Secondly, materiality, virtual realm and spirit of the technology provide elementary levels at which human and material agencies entangle. Lastly, the elementary levels at which human and material entangle depends on the capabilities or skills set of an individual.
\end{abstract}

Keywords: cloud computing, sociomateriality, IT workers, materiality, organizational change, organizational routines, On-premise IT system, Software as a service (SaaS)

Paper type: Conceptual

Mbuba, F., Wang, W. Y. C., \& Olesen, K. (2015). Sociomateriality Implications of Software as a Service Adoption on IT-Workers' Roles and Changes in Organizational Routines of IT Systems Support. In L. Wang, S. Uesugi, I. H. Ting, K. Okuhara, \& K. Wang (Eds.), Multidisciplinary Social Networks Research: Second International Conference, MISNC 2015, Matsuyama, Japan, September 1-3, 2015. Proceedings (Vol. 540 of Communications in Computer and Information Science, pp. 249-263): Springer Berlin Heidelberg. Doi: 10.1007/978-3-662-48319-0_20

\section{Introduction}

Software as a service (SaaS) adoption has the potential to change IT workers' roles and skill set requirements as well as organizational routines of IT systems support. The conceptualization of the relationship between the social and the technological has been a recurring concern in information systems (IS) research, not only in how human interact with the material, but also the mutually constitutive relationship between social practices and materiality $[1,2]$. In this paper, we combine the sociomateriality perspective [3] and the organizational routines theory [4] to understand how sociomateriality practices influence IT workers' roles and skill set requirements and changes in the organizational routines of IT systems support. Where the term materiality refers to "the arrangement of an artifact's physical and/or digital materials into particular forms that endure across differences in place and time" [2]. Similarly, Leonardi defines sociomateriality as the "enactment of a particular set of activities that meld materiality with institutions, norms, discourses, and all other phenomena we typically define as social" [5]. Therefore, the sociomateriality perspective examines the role of materiality in social life [5] and its implications on organizational routines [6]. Feldman and Pentland define an organizational routine as a "repetitive, recognizable pattern of interdependent actions, involving multiple actors" [4]. An organizational routine is the primary means by which organizations accomplish what they do. The sociomateriality perspective is useful in explaining how organizational and technological changes are interwoven [7] and how the social and material are entangled in practice [3]. The sociomateriality perspective has not sufficiently examined and linked changes in organizational routines with changes in the materiality of work practices in SaaS context [3].

The SaaS business model refers to a hosted software application delivered online via the Internet and accessed through a web browser [8]. The SaaS business model is proven useful because it has the potential to change IT workers' roles and skill set requirements, and the organizational routines of IT systems support [9]. More specifically, by using the sociomateriality perspective [3], this conceptual paper examines how materiality inscribes aspects of social structures [7] on IT workers and on the organizational routines [4] of IT systems support, when an organization moves an on-premise IT system to SaaS business model. An on-premise IT system is a software service model in which customers purchase permanent licenses of the commercially available software, and the organizations IT workers maintain the application and the infrastructure associated with it. We present initial findings of interpretive case studies from New Zealand tertiary institutions, of the migration of onpremise emailing system to SaaS business model, such as Google Apps for Education and Microsoft Office 365. 


\subsection{Research Context: SaaS Business Models in Tertiary Institutions}

Many organizations, such as tertiary institutions, have embraced the use of SaaS business model, such as Google Apps for Education and Microsoft Office 365 [10]. This is because in these institutions, migrating on-premise IT systems to SaaS business model provide improved real-time collaboration and research capabilities, at reduced costs while providing better levels of computing services to faculty members [10].

Exaggerated by the need to cut overhead costs at a time when public and private institutions are coping with significant budget shortfalls, the massification of higher education, globalization effects, the advent of the knowledge society, and IT capabilities [11]. On massification, governments demand for expansion of enrolment that has taken place worldwide, while tertiary institutions are coupled with a financial struggle to meet the need for an enlarged infrastructure and a larger teaching staff [11]. Globalization has shaped the world through factors such as an integrated world economy, new IT innovations, the emergence of an international knowledge network, and the rise of English as the universal language of scientific communication. These factors of globalization have increased student mobility worldwide [11] and consequently have affected the tertiary education sector globally. Institutions have implemented a variety of policies and programs to respond to them. These include, setting up branch campuses overseas, internationalizing curricula, engaging in international partnerships, and the use of latest IT innovations-to enhance real-time collaboration and research capabilities, as well better computing powers at reduced costs [11].

The SaaS business model, therefore, allows institutions not only to reduce IT infrastructural costs and tap into latest IT innovations from commercial cloud service providers via the Internet, but as well many of these resources are available to them either for free or at reduced costs [10].

With the SaaS business model, students and faculty staff take advantage of the ability to undertake research and collaborate with international researchers from anywhere and on any device using SaaS applications. Other benefits SaaS provides to customers include: no upfront investment cost required, elasticity of computing resources, vendor support and upgrades, agile response to markets, usage metered as a utility, resource pooling and the ability to add computing resources as needed [12]. As a result, organizations adopt the SaaS business model based on these potential benefits. However, these benefits may have some implications on the IT workers and on the organizational routines of IT systems support. These implications might include: changing IT workers' roles and skill set requirements, widespread of layoffs of hardware IT workers, and IT department lose control of IT-Servers, and focusing more on data security, vendor management, as IT systems support moves to cloud service providers [8]. The migration of on-premise IT system to the SaaS business model therefore, is proven to be useful in understanding how technological changes influence changes in organizational routines of IS work practices [3]. To control the diversity of various types of SaaS systems, cases were selected based on being on-premise emailing systems that had migrated to similar SaaS emailing systems across tertiary institutions in New Zealand.

\subsection{Research Purpose}

There is a lack of research conducted on the implications of the SaaS business model on organizational routines and related human resource management [13], as well as the linked changes in organizational routines with changes in the materiality of IS work practices [3]. Drawing on organizational routines theory [4], and the sociomateriality perspective [2], this paper therefore, seeks to fill this gap in the literature by examining how SaaS adoption, may trigger variations in performative actions in organizational routines of IT workers during IT systems support [14].These variations in performative actions may be institutionalized resulting in changes in organizational routines. This ongoing study extends earlier work on the implications of artifacts on organizational routines [13], and demonstrates the performative to ostensive change which accounts for the effects such as creation, maintenance or modifications of the organizational routines [4]. In addition, using the sociomateriality lens, this study examines the entanglement between human and material agencies in an on-premise IT system and in the SaaS environment [15].

By studying how technological changes from on-premise IT system to SaaS business model occurs, the inscribing features of social structures on IT workers' roles and skill set requirements, and on the organizational routines of IT systems support, our aim is to answer the following research questions:

1. At what materiality level does human and material agencies entangle?

2. What social outcomes do these entanglements produce in on-premise IT systems and SaaS contexts?

3. How can technological artifact entangled in sociomaterial practices, influence the changes on IT workers' roles and skills set requirements, and on the organizational routines of IT systems support?

The paper is structured as follows: First, we review SaaS business model. Thereafter, a theoretical review on the sociomateriality and organizational routines theory. Subsequently, we discuss research methodology. The paper concludes with a discussion of contributions and limitations of our paper, and future research directions. 


\section{SaaS Business Model}

SaaS is one of the cloud computing services levels. Here cloud computing refers to applications delivered as services over the Internet and have infrastructure in data centers that enable these services [16]. Other cloud services levels include, hardware as a Service (HaaS), Infrastructure as a Service (IaaS) and Platform as a Service (PaaS) [12]. Extant IS literature discuss these services in much depth [17, 18]. This study however, focuses on the SaaS business model, not only because of the elasticity, multitenancy configurability, and ubiquitous features that SaaS offers to adopting organizations, but also, it represents a huge transformation in the way organizations use and support IT services $[8,9]$.

\section{Theoretical Review}

We briefly review theoretical lenses used in this study, sociomateriality and the organizational routines theory, followed by research methodology.

\subsection{Sociomateriality Perspective}

Technology presents a conceptual challenge when faced with complex materiality of everyday IS- mediated work practices [3, 5, 19]. IS researchers, have encountered this challenge in studying the relationship between materiality and human, or technology and social life, and how this contributes to organizational change [1, 3, 5]. In this endeavor therefore, IS scholars have coined a term sociomateriality, that describes the constitutive entangling of the material and social in work practice [3].

Sociomateriality thinking roots from sociotechnical systems thinking [20], actor network theory [21] and practice theory [22]. Two ontologies guide the sociomateriality thinking- relational ontology [1, 19] and substantiality ontology [5]. Relational ontology of sociomateriality assumes that "social and material are inherently inseparable" [1]. It challenges the separation of material from human or technology from social life. This represents a shift from understanding people and technologies, each characterized by specific properties and boundaries that interact and mutually impact each other in the performative nature of practices when are enacted and re-enacted [22].

Substantiality ontology on the other hand, takes the notion of "substances of various kinds (things, beings, essences)" as self-subsistent entities, which come preformed and involve themselves in dynamic relations [23]. According to substantiality views, materiality is inherent to technology, independent of its use and the context in which technology is used [15]. Leonardi argues that once technology is built its materiality is fixed, unless some subsequent redesign is undertaken [5]. When implemented in an organizational context, a technology's materiality becomes important, because users react to the technology's materiality - a materiality they perceived as bounded and stable - when translating it from the realm of the artifactual into the realm of the social [2].

This paper takes the substantiality ontological stance, in understanding the intertwining of human and material agencies and how this bring changes in the organizational routines [2]. According to Leonardi, "routines and technologies are the infrastructure that the imbrication of human and material agencies produce" [7]. Here "imbrication" describes the ways human and material agencies intermingle to create or change routines, or alter technologies [7]. Imbrication is useful in two ways: First, it suggests that human and material agencies are effectual at producing outcomes (e.g. routines or technologies), only when are joined together, but their interdependences does not alter their specificity and distinct characters [7]. In other words, "people have agency and technologies have agency, but ultimately, people decide how they will respond to a technology" [7]. Secondly imbrication reminds us that all interactions between human and material agencies produce "organizational residue", such as routines or technologies and these figurations persist absent of their creators [7].

\subsection{Organizational Routines Theory}

Organizational routines are an essential aspect of organized work, a source of inertia, inflexibility and mindlessness [4]. In addition, organizational rules and routines have been seen as a source of accountability, political protection, and a source of stagnation. Routines enable bureaucracies to organize expertise and exercise power efficiency [4]. For example, in order to effectively support IT users, the IT-department has designed an organizational routine - the IT systems support to cater for user support. IT systems support allows any IT user to $\log$ a job to the IT-helpdesk, for any IT related request or a faulty piece of hardware to be fixed. The jobs are executed by IT workers in hierarchical manner from IT technicians at the helpdesk (known as first tier IT support 
level), to systems engineers and IT-experts at the second tier, which could be escalated to the third and fourth tier IT-support levels [24].

The organizational routine comprises two intertwined aspects (shown on Figure 1) known as performative and ostensive [4]. Performative (or agency) aspect describes the actual actions of the routine by specific people, at specific times, in specific places $[4,25]$. The role of performative aspects bring subjectivity and power into organizational routines and involves the ability to remember the past, imagine the future, and respond to present circumstances [4]. Thus, the performance of routines involve adapting to contexts that require either idiosyncratic or ongoing changes and reflecting on the meaning of actions for future realities [4].

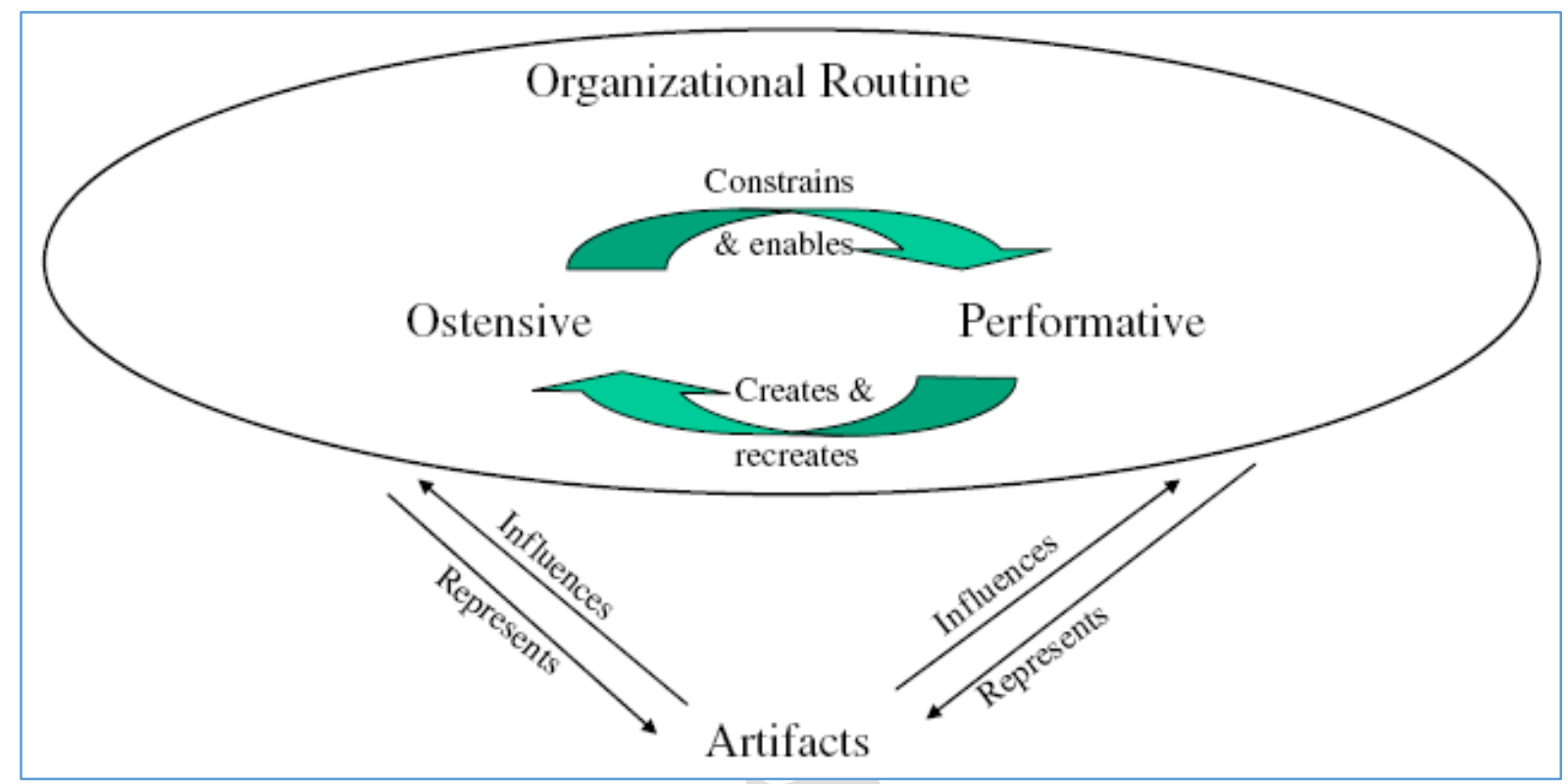

Figure 1 Organizational routines are generative systems [6].

Ostensive defines the structure or abstract idea of routines [4]. It describes abstract regularities and expectations that enable participants to guide, account for, and refer to specific performances of a routine [6]. Ostensive aspects are not written rules or procedures, but rather consists of the understandings embodied and cognition of the actors [6]. Artifacts associated with the organizational routines may attribute variations in performative aspects, [4, 14]. Artifacts take forms like written rules, procedures, or IT systems. In an organizational routine, artifacts are used to ensure the reproduction of particular patterns of action [6].

For example, an IT-department has setup a web based IT system support to help fix IT users' problems in an effective, efficient and accountable manner. However, this technology can been seen as enabling and constraining action [26]. The ostensive and performative aspects, therefore, are produced and reproduced through actions taken by actors and the actions taken are constrained and enabled by structure [25]. Hence, these aspects of organizational routines are viewed as recursively related, with the performances creating and recreating the ostensive aspect and the ostensive aspect constraining and enabling the performances [4].

The relationship between ostensive and performative aspects of routines therefore, create an on-going opportunity for variation, selection and retention of new practices and patterns of actions within routines and allows routines to generate a wider range of outcomes from apparent stability to considerable change [27].

\section{Research Methodology}

In this ongoing study, the empirical data was obtained through semi-structured interviews with IT workers of their experiences and events, when migrating on-premise IT-system to SaaS business model. We conducted a multisite, interpretive case study [28] in four tertiary institutions in New Zealand to investigate how the technology changed IT workers roles and skill set requirements and functions of the organizational routines of the IT systems support, during the adoption of SaaS business model [4].

We used both primary and secondary sources of empirical evidence. Semi structured interviews and field notes are among the primary sources of data, while the secondary sources of data came from official documentation and published information.

The semi-structured interviews assisted us in uncovering understandings of series of events, stories, and experiences [29] from IT workers and IT managers involved in migrating on-premise IT system to a SaaS business 
model. In total 17 interviews were conducted, of which four of the interviewees were IT managers, seven systems engineers and six IT technicians. All of those interviewed were involved in the on-premise IT systems migration project and supporting the SaaS business model.

The principles of data coding and hermeneutic circles were used for data analysis within and cross-cases [28], to identify situations in which human and materiality entanglements were seen to be significant in maintaining IT systems support. These human and material entanglements were analyzed in relationship with the five notions of sociomateriality [30].

\section{Analysis and Discussions}

Our discussions aim is to answer the following research questions:

1. At what materiality level does human and material agencies entangle?

2. What social outcomes do these entanglement produce in on-premise IT systems and SaaS contexts?

3. How can technological artifact entangled in sociomaterial practices, influence the changes on IT workers' roles and skills set requirements, and on the organizational routines of IT systems support?

First we discuss the imbrication of human and material agencies, followed by how technological artifacts entangled in sociomaterial practices, influence the changes of IT workers' roles and skill set requirements and performative and ostensive aspects of organizational routines.

\subsection{Imbrication of Human and Material Agencies}

Following the principles of chemistry, matter exists in three basic forms: solid, liquid, and gaseous forms [31, 32]. Principally, it's at these forms human may imbricate with the material artifact [31]. Human and material agencies therefore imbricate: physically, at the virtual realm and the spirit levels. For example, a car driver imbricates with a car at least physically, while a non-driver, for instance a car enthusiast, imbricates with cars virtually, whereas a car designer imbricate with cars at the spirit level (the essence of the car to meet the users' requirements, affordances, look and feel), as well as physically and in a virtual realm. In the same vein, this paper, argues that human and material agencies imbricate at three different elementary levels: materiality, virtually and/or at spirit (essence) level of sociomateriality. Our initial findings consistently show how IT technicians, systems engineers and IT managers imbricate differently with technology at materiality, virtual and spirit of the technology.

\subsubsection{Materiality of Technology}

Materiality is not only inherent to technology, independent of its use and the context in which technology is used [15], but it is also a point of imbrication of human and material agencies. In other words, materiality provides affordances and constrains to accord imbrication of human and material agencies to happen [33]. For "materiality" to exist as a concept separate from "sociomateriality", implies that some materials are not simultaneously social [2]. Our study shows IT workers perform well within the materiality of IT, that is the hardware and software of the IS, in terms of IT systems' maintenance and support.

\subsubsection{Virtual Realm of Technology}

The virtual realm of technology [34], relates to technological features that are malleable and changes per system use. Unlike, materiality of technology, virtual features are inherent of technology, but depends on context and use of technology. For example, unlike on-premise IT systems built on a client-server architecture, SaaS business model has characteristics of utility features, such as: configurability, multitenancy, elasticity, scalability and ubiquitous, and it's a web-based application accessible via a browser [8]. This does not mean that traces of them did not necessarily exist in client-server architecture of the on-premise IT systems, but the richness, malleability and ease integrations through application programming interfaces (APIs) with other IT-systems created a different abstraction layer of technology, hence SaaS demands different IT workers' skills to maintain and support. Our study consistently shows how IT technicians and systems engineers imbricate differently at the virtual realm of technology.

\subsubsection{Spirit of Technology}

Spirit of technology refers to the essence or strategic goals of the technology [35]. Spirit can be identified by analyzing the philosophy of the technology based on the design metaphor underlying the system (e.g., SaaS is ubiquitous-anywhere and on any device access via Internet browsers). The spirit of technology can also be identified by the features it incorporates and how they are named and presented (e.g., elasticity, scalability, configurability and multitenancy of SaaS applications). Spirit can also be seen through the nature of the user interface (e.g., SaaS is web-based) and training materials and online guidance facilities (e.g., dashboards and 
online tutorials). Lastly spirit of technology can be seen through the systems support and maintenance (e.g., vendor maintains and supports SaaS applications) and integrations with other systems (e.g., use of web-services and APIs) [35].

Our initial findings show IT managers imbricate with technology at the spirit level, by enforcing organizational routines to meet the organization's strategic goals of the technology.

\section{For example:}

Our findings indicate that IT technicians are more inclined to support and maintenance of the IT system-both hardware and software components. IT technicians therefore, tend to follow IT system support routines on "how to" fix the system, and thus imbricating with the materiality of the technology. Systems engineers, however, tend to think of the design architecture of the IT system and "why" it is behaving as it is. Systems engineers, therefore have an ability to change the system's code, to align with the organizational needs. The coding skills enable systems engineers to manage system changes from on-premise IT system to SaaS model more efficiently, than the IT technicians. Our empirical data shows that IT managers imbricate with the technology at spirit level-by analyzing the purpose of the system. IT managers use organizational routines to enforce rules and guidelines, and to ensure the system meets its strategic goals.

Following Orlikowski and Scott [1], Jones discusses five main notions of sociomateriality: materiality, inseparability, relationality performativity and practice [30]. Materiality describes physical, digital and nonphysical features of material artifacts that does not change over time and space [2]. Inseparability explains whether human and material agencies exist as separate or inseparable entities [1]. Relationality describes whether imbrications of human and material agencies have any "analytical boundaries" [1]. Performativity explains the ability of human and material agencies to achieve social outcomes [30]; and practice discusses the forms of bodily, and mental activities, things and their use in form of understanding, states of emotion and motivational knowledge [30].

To gain deeper understanding of the social outcomes, this study examines further, on the imbrication of human and material agencies at these elementary levels (materiality, virtual and spirit) with respect to five notions of sociomateriality [30]. Our discussions in the context of the implications of SaaS business model on IT workers' roles and skill set requirements and changes in organizational routines of IT-system support are summarized in Table 1. In building Table 1, we ask what it means with respect to five notions of sociomateriality, when human and material agencies imbricate at materiality, virtual and/or spirit levels of technology, in the context of both onpremise IT systems and SaaS business models?

\subsection{Changes in Organizational Routines}

\subsubsection{Selective Variations (Performative to Ostensive Changes)}

The performative aspect of routines is critical for creation, maintenance and modifications of the ostensive aspects. Actors might alter the performative aspects (actions or performances) that the ostensive aspect of the routine guides or accounts for [4]. Thus, performative aspects enact ostensive aspect of the routine as an unintended effect of action $[25,26]$. The variations in performative actions therefore, might be institutionalized into and alter ostensive aspects of the organizational routine and hence bring organizational change [6].

For example, IT workers might change the way IT systems support is performed. For instance, when an IT user logs a job at the IT technician help-desk, IT technicians then advises an IT user to call a second tier support systems engineer directly instead. Then the systems engineer solves a problem and closes the job. Subsequent IT users' requests bypass IT helpdesk and calls second tier support directly. The trend might continue until it becomes a norm in solving such a problem. These performative actions might be institutionalized into ostensive aspects of the organizational routine and bring effects such as creation, maintenance and modification of organizational routines, and bring changes to a larger organizational context as part of relevant actions that IT workers take in organizational routines .

In this example, the motivation of IT workers performing user support is not to create, maintain or modify the ostensive aspect of the routine, but rather aim to fix a computer problem logged by a user. However, some outcomes of engaging in actions has some effect on the structure (ostensive) that constrain and enable further actions [4].

\subsubsection{Selective Retention (Ostensive to Performative Changes)}

Actors can use the ostensive aspect of routines as a guide on how actions ought to be taken, or for accounting actions already taken [4]. The use of the ostensive aspect in relation to the performative aspect of routine is referred to as "guiding, accounting and referring" [4]. Employers, and authorities use guiding, accounting and referring to exert power over their own people's performances to signify that some performances are part of a recognizable routine and to legitimate some performances as appropriate to that routine [4]. 
Table 1: Human and Material Agencies Imbrications Levels

\begin{tabular}{|c|c|c|c|c|c|}
\hline \multirow{3}{*}{$\begin{array}{l}\text { Human/material } \\
\text { Agencies } \\
\text { Imbrication Levels } \\
\quad \text { Materiality }\end{array}$} & \multicolumn{5}{|c|}{ Notions of Sociomateriality [30] } \\
\hline & Materiality & Inseparability & Relationality & Performativity & Practice \\
\hline & $\begin{array}{l}\text { Technician level-supporting hardware and } \\
\text { software of IT. This level requires experience } \\
\text { and know 'how' skills and capabilities. } \\
\text { Human/material imbricated at material level, } \\
\text { materiality of technology remains unchanged } \\
\text { over differences in time and places, } \\
\text { Example: In SaaS business model, the } \\
\text { hardware relocates to data centers ("cloud"), } \\
\text { and software accessed via a web-based } \\
\text { virtualized abstraction layer }\end{array}$ & $\begin{array}{l}\text { Human/material agencies remain } \\
\text { independent entities from one another } \\
\text { when imbricating at materiality level. } \\
\text { Example: IT technician may decide to } \\
\text { restart the IT-system, otherwise will } \\
\text { remain 'on' unless some physical and } \\
\text { electronic fault occurs. }\end{array}$ & $\begin{array}{l}\text { There is a clear boundary between } \\
\text { human/material agencies at } \\
\text { materiality level. Human and } \\
\text { material agencies emerge in their } \\
\text { imbrication in specific practices } \\
\text { [2].Example: Human agency or } \\
\text { an IT-system's faulty calling for } \\
\text { human intervention might initiate } \\
\text { social activities. }\end{array}$ & $\begin{array}{l}\text { Human/material agencies } \\
\text { have capabilities to } \\
\text { achieve "social outcomes" } \\
\text { [2]. Activities are } \\
\text { interpreted physically, } \\
\text { digitally and by non- } \\
\text { physical means. } \\
\text { Example: Human agency } \\
\text { might initiate software } \\
\text { application to run or be } \\
\text { installed. The software } \\
\text { runs to produce desired } \\
\text { outcomes. }\end{array}$ & $\begin{array}{l}\text { Ability to initiate } \\
\text { human/material activities } \\
\text { were different during the on- } \\
\text { premise and SaaS systems. } \\
\text { Example: Our findings show } \\
\text { IT technicians and systems } \\
\text { engineers have different } \\
\text { capabilities to engage with } \\
\text { SaS system. IT technicians } \\
\text { altered certain organizational } \\
\text { routines to circumvent direct } \\
\text { support on SaaS }\end{array}$ \\
\hline Virtually & $\begin{array}{l}\text { When human and material agencies imbricate } \\
\text { at virtual level, the materiality of technology is } \\
\text { seen to be malleable. At this level, IT workers } \\
\text { need to understand 'why' the system behaves } \\
\text { that way and demands deeper IT skills, such as } \\
\text { coding skills. Our findings show imbrication at } \\
\text { this level is predominately common in SaaS } \\
\text { than in an on-premise IT system. Example: IT } \\
\text { technician failing to troubleshoot SaaS systems } \\
\text { and escalates these issues to systems engineers, } \\
\text { showing most IT technicians were unable to } \\
\text { imbricate at virtual realm of IT. }\end{array}$ & $\begin{array}{l}\text { Imbricating at virtual realm of } \\
\text { technology, human/material agencies } \\
\text { remain separable and independent entities } \\
\text { across space and time [2]. Example: } \\
\text { Multitenancy, elasticity and scalability } \\
\text { features of Saas systems remain } \\
\text { independent from IT workers' } \\
\text { interventions, and material performances } \\
\text { as these features follow prescribed IT } \\
\text { settings. }\end{array}$ & $\begin{array}{l}\text { Analytical boundaries exists } \\
\text { between human/material agencies } \\
\text { imbricated at virtual realm of } \\
\text { technology [2]. Example: } \\
\text { Though Saas has multitenancy, } \\
\text { elasticity and scalability features, } \\
\text { these exist independent of the } \\
\text { designer following virtualization } \\
\text { characteristics of IT. }\end{array}$ & $\begin{array}{l}\text { Human/material agencies } \\
\text { have capabilities to } \\
\text { achieve social outcomes in } \\
\text { non-physical and digital } \\
\text { means. Example: The } \\
\text { scaling up or down of IT } \\
\text { resources by SaaS system } \\
\text { achieves social outcomes } \\
\text { as a utility to IT users. }\end{array}$ & $\begin{array}{l}\text { Human/material agencies } \\
\text { imbricated at virtual realm- } \\
\text { tend to operate at coding } \\
\text { layer. Example: Systems } \\
\text { engineers creates APIs to } \\
\text { integrate with other } \\
\text { organizational systems }\end{array}$ \\
\hline Spirit & $\begin{array}{l}\text { Human/material agencies imbricated at spirit } \\
\text { level calls for IT managers to understand the } \\
\text { ability of materiality of technology to meet the } \\
\text { organization's strategic goals. Example: IT } \\
\text { manager opted for Serverless (SaaS) system to } \\
\text { cut down operational and human resource costs } \\
\text { as well as tap into latest cloud based } \\
\text { technologies. }\end{array}$ & $\begin{array}{l}\text { At the spirit level, human/material } \\
\text { agencies imbrication becomes } \\
\text { inseparable. As at this level, "social and } \\
\text { material becomes inherently inseparable" } \\
\text { [1]. In other words, managers' "quotidian } \\
\text { interaction" [2] with technology becomes } \\
\text { a subconscious norm of everyday life. } \\
\text { Example: IT managers concerns of on- } \\
\text { premise IT system's inability to meet } \\
\text { users' expectations were a major concern } \\
\text { in their social work life. As it was for } \\
\text { Steve Jobs and is for Bill Gates imbricated } \\
\text { at spirit levels to Apple and Microsoft } \\
\text { products respectively. These men and } \\
\text { their products are inseparable. }\end{array}$ & $\begin{array}{l}\text { When human/material agencies } \\
\text { imbricate at spirit level, the } \\
\text { assemblage "dissolves analytical } \\
\text { boundaries between human and } \\
\text { technology" [1]. Human/material } \\
\text { agencies exist in an intricate } \\
\text { assemblage of the human's mind. } \\
\text { Example: IT managers shared } \\
\text { their on-premise IT systems' } \\
\text { problems with colleagues, family } \\
\text { members and outsiders/vendors to } \\
\text { solicit insights for a } \\
\text { comprehensive solution. }\end{array}$ & $\begin{array}{l}\text { Human/material agencies } \\
\text { imbricated at spirit level, } \\
\text { forms a human/material } \\
\text { assemblage recursively } \\
\text { intertwined, having a } \\
\text { resultant social outcome. } \\
\text { Example: Our study } \\
\text { shows that IT managers } \\
\text { embodied with troubled } \\
\text { technological issues, have } \\
\text { a strong decisive desire to } \\
\text { make changes to the } \\
\text { system. }\end{array}$ & $\begin{array}{l}\text { With relation to practice, } \\
\text { human/material imbrication } \\
\text { at spirit level remains an } \\
\text { enthusiastic stance and } \\
\text { differs among individuals. } \\
\text { Example: Our study } \\
\text { consistently shows that IT } \\
\text { managers were enthusiastic } \\
\text { in migrating on-premise IT- } \\
\text { system to SaaS model. }\end{array}$ \\
\hline
\end{tabular}


Guiding serves as a template for behavior or a goal [4]. For example, IT managers enforce the use of IT system support structures to accomplish any task. Accounting allows actors to explain what they are doing in ways that make sense of their activities [4]. It provides ready-made justification for actions that seem unusual and provides reasonable accounts when called to explain [4]. Referring ostensive aspect of routines, therefore, helps to refer to pattern of activity that would otherwise be incomprehensible. For example, IT workers referring to systems manuals and user guides to accomplish certain tasks

With the introduction of the SaaS business model changes occurred in the ways human and material agencies imbricate at the materiality, virtual realm and spirit level of technology. These imbrications between human and material agencies produce "organizational residue" - organizational routines or technologies and these figurations persist absent of their creators [7]. Similarly, the recursive nature of performative and ostensive aspects of organizational routines brings organizational change (see Figure 2). Both changes in organizational routines and organizational residues might be institutionalized to form a new sociomateriality assemblage, as illustrated in figure 2 .

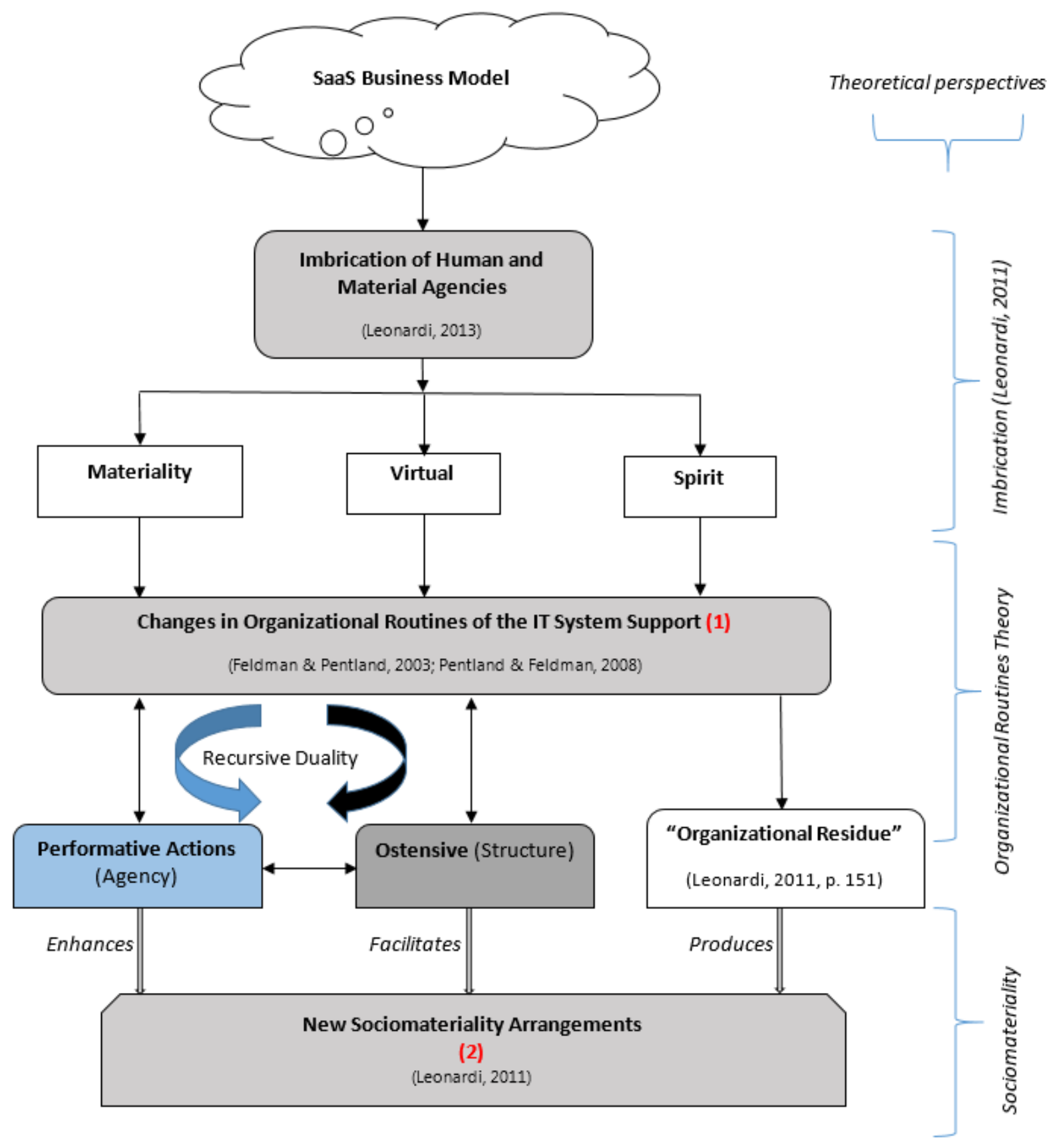

Figure 2: Implications of SaaS Business Model 


\section{Conclusion}

Our study examined theories of organizational routines and the sociomateriality perspective of the SaaS business model that remain an under-explored topic. Past IS research on implications of cloud computing on human resources, have explored general implications without paying particular attention on specific service levels [18]. The exception is study that examined the implications of SaaS adoption on organization's operations and business [9]. His study however, did not address how organizations were affected due to new social structures of the SaaS business model. Further, he did not account for the events and processes that led to organizational changes. To answer our research questions, this paper has demonstrated that (1) human and material agencies imbricates/entangles at materiality, virtual realm and/or the spirit of technology. The imbrications though, depend on the capabilities or skill sets of an individual; (2) The imbrications produce varied social outcomes, such as routines or new technologies as organizational residues; (3) The influences of sociomaterial practices varies, depending on individual's capabilities when imbricates with artifact at either materiality, virtual realm and/or the spirit of technology.

\subsection{Contributions}

Our study makes three contributions. Firstly, we show the way technological artifacts, which are entangled in sociomaterial practices can change the way human responds to the performative aspects of the organizational routines. Leonardi supports this that "human and material agencies interweave in ways that create or change routines..."[7]. Secondly, we demonstrate how materiality, virtual realm and spirit of the technology provides elementary levels at which the human entangles with material. Thirdly, we show that the elementary levels at which human and material entangle depends on the "capability" [5] or skill set of an individual.

\subsection{Limitations}

The study has several limitations. First, it is a multi-case study in need of further in-depth longitudinal studies. Second, the unique nature of SaaS business model needs to be further examined associated with other technologies. Third, this study accounts for individual experiences of IT workers, and does not account for a wider range at an organizational level. This paper, however, examined IT workers experiences at the project level.

\subsection{Future Research}

We suggest several opportunities for future research. First, to extend the organizational routines theory we need to examine the changes in IT systems support with other IT technologies. Second, there possibly other organizational routines changes on IT systems management. Third, we suggest deeper examination of other microlevel routines that might inform how performative and ostensive aspects of routines changes, due to the introduction of new technologies. Finally, further examination of changes in organization routines as a result of changes in sociomateriality of technology in different contexts could be explored.

\section{References}

1. Orlikowski, W.J. and S.V. Scott, Sociomateriality: challenging the separation of technology, work and organization. Annals, 2008. 2: p. 433-474.

2. Leonardi, P.M., Theoretical foundations for the study of sociomateriality. Information and Organization, 2013. 23(2): p. 59-76.

3. Orlikowski, W.J., Sociomaterial practices: Exploring technology at work. Organization Studies, 2007. 28(9): p. 1435-1448.

4. Feldman, M.S. and B.T. Pentland, Reconceptualizing Organizational Routines as a Source of Flexibility and Change. Administrative Science Quarterly, 2003. 48(1): p. 94-118.

5. Leonardi, P.M., Materiality, Sociomateriality, and Socio-Technical Systems: What Do These Terms Mean? How Are They Related? Do We Need Them?, in Materiality and Organizing: Social Interaction in a Technological World P.M. Leonardi, B.A. Nardi, and J. Kallinikos, Editors. 2012, Oxford University Press.: Oxford. p. 25-48.

6. Pentland, B.T. and M.S. Feldman, Designing routines: on the folly of designing artifacts, while hoping for patterns of action. Information and organization, 2008. 18(4): p. 235-250. 
7. Leonardi, P.M., When flexible routines meet flexible technologies: Affordance, constraint, and the imbrication of human and material agencies. MIS Quarterly: Management Information Systems, 2011. 35(1): p. 147-167.

8. Carraro, G. and F. Chong. Software as a service (SaaS): An enterprise perspective. Microsoft Corporation. 2006 [cited 2012 July 14]; Available from: http://msdn.microsoft.com/enus/library/aa905332.aspx.

9. $\mathrm{Wu}, \mathrm{W} . \mathrm{W}$., Mining significant factors affecting the adoption of SaaS using the rough set approach. The Journal of Systems \& Software, 2011. 84(3): p. 435-441.

10. Wyld, D.C. and R.L. Juban, Education in the Clouds: How Colleges and Universities are Leveraging Cloud Computing, in Technological Developments in Networking, Education and Automation, $\mathrm{K}$. Elleithy, et al., Editors. 2010, Springer Science+Business Media B.V.: Springer Netherlands. p. 1-6.

11. Altbach, P.G., L. Reisberg, and L.E. Rumbley, Tracking a global academic revolution. Change: The Magazine of Higher Learning, 2010. 42(2): p. 30-39.

12. Mell, P. and T. Grance, The NIST definition of cloud computing (draft). NIST special publication, 2011. 800(145): p. 1-7.

13. Lyytinen, K., G. Rose, and Y. Yoo, Learning routines and disruptive technological change: Hyperlearning in seven software development organizations during internet adoption. Information Technology and People, 2010. 23(2): p. 165-192.

14. Feldman, M.S., Organizational Routines as a Source of Continuous Change. Organization Science, 2000. 11(6): p. 611-629.

15. Barley, S.R. and P.M. Leonardi, Materiality and change: challenges to building better theory about technology and organizing. Information and organization, 2008. 18(3): p. 159-176.

16. Wyld, D.C., Risk in the clouds?: Security issues facing government use of cloud computing, in Innovations in Computing Sciences and Software Engineering. 2010, Springer. p. 7-12.

17. Benlian, A., T. Hess, and P. Buxmann, Drivers of SaaS-Adoption - An Empirical Study of Different Application Types. Business \& Information Systems Engineering, 2009. 1(5): p. 357-357.

18. Cusumano, M., Cloud computing and SaaS as new computing platforms. Communications of the ACM, 2010. 53(4): p. 27.

19. Barad, K.M., Meeting the universe halfway: quantum physics and the entanglement of matter and meaning. 2007, Durham, N. C: Duke University Press.

20. Mumford, E., The story of socio-technical design: reflections on its successes, failures and potential. Information Systems Journal, 2006. 16(4): p. 317-342.

21. Latour, B., Reassembling the social: an introduction to actor-network-theory. 2005, Oxford [England]: Oxford University Press.

22. Cecez-Kecmanovic, D., et al., The Sociomateriality of Information Systems: Current Status, Future Directions. MIS Quarterly, 2014. 38(3): p. 809-830.

23. Emirbayer, M., Manifesto for a Relational Sociology 1. American Journal of Sociology, 1997. 103(2): p. 281-317.

24. Gao, F., X. Qiu, and L. Meng. SLA based business-driven adaptive QoS maintenance mechanism for multi-tier service in virtualized IT environment. in GLOBECOM Workshops (GC Wkshps), 2010 IEEE. 2010 .

25. Giddens, A., The constitution of society: outline of the theory of structuration. 1984, Cambridge, England: Polity Press.

26. Orlikowski, W.J., Using technology and constituting structures: A practice lens for studying technology in organizations. Organization Science, 2000. 11(4): p. 404-428.

27. Pentland, B.T. and H.H. Rueter, Organizational Routines as Grammars of Action. Administrative Science Quarterly, 1994. 39(3): p. 484-510.

28. Myers, M.D., Qualitative research in business \& management. 2011, London: SAGE.

29. Walsham, G., Interpretive case studies in IS research: nature and method. European Journal of information systems, 1995. 4(2): p. 74-81.

30. Jones, M., A matter of life and death: exploring conceptualizations of sociomateriality in the context of critical care. Management information systems, 2014. 38(3): p. 895-925.

31. Blin-Stoyle, R.J., Eureka!: physics of particles, matter and the universe. 1997: CRC Press.

32. Ursul, A., Informational and cosmological foundations of the cybernetic systems security phenomenon. Scientific and Technical Information Processing, 2008. 35(2): p. 87-98.

33. Markus, M.L. and M.S. Silver, A Foundation for the Study of IT Effects: A New Look at DeSanctis and Poole's Concepts of Structural Features and Spirit. Journal of the Association for Information Systems, 2008. 9(10): p. 609-632.

34. Wetmore, A., The Poetics of Pattern Recognition: William Gibson's Shifting Technological Subject. Bulletin of Science, Technology \& Society, 2007. 27(1): p. 71-80. 
35. DeSanctis, G. and M.S. Poole, Capturing the complexity in advanced technology use: Adaptive structuration theory. Organization Science, 1994: p. 121-147.

\section{Authors' Biography}

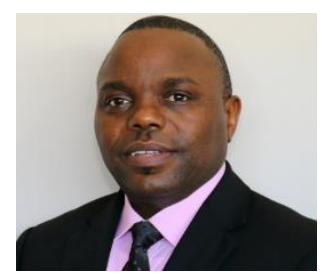

Freddie Mbuba is a doctoral candidate in information systems at Faculty of Business and Law, Auckland University of Technology, New Zealand. He received his BSc in mechanical engineering from University of Dares-Salaam, Tanzania, MBA from Management College of Southern Africa (MANCOSA), South Africa. His research focuses on utilizing qualitative research approaches; both positivist and interpretivist, to study the implications of cloud computing and organizational change, mobile collaboration, and on-line education. His alternative email is: mbubaf@gmail.com

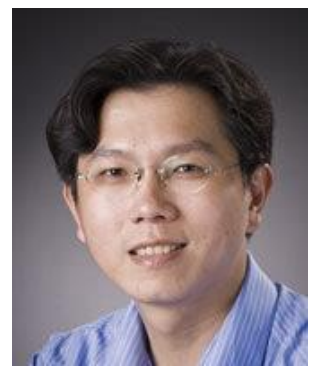

Associate Professor William Y C Wang, who is a full time faculty member at the Department of Business Information Systems, Faculty of Business and Law, Auckland University of Technology, has supervised research projects and provided industrial consultancy in Australasia and Asian regions regarding cloud based computing, social media strategy, supply chain management and planning, and business process re-engineering. He also has experiences in practical projects in Enterprise Systems such as the planning of implementing SAP and MS Dynamics. These projects have specifically highlighted on the interdisciplinary issues related to B2B integration, enterprise systems adoption \& maintenance, and supply chain configuration for large firms and SMEs. His email contact is William.Wang@aut.ac.nz

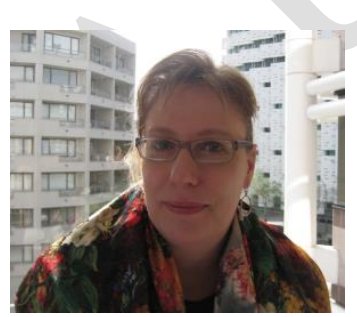

Dr Karin Olesen is a full time faculty member at the Department of Business Information Systems, Faculty of Business and Law, Auckland University of Technology. Her research interests are in information systems design and management in a diverse range of functional areas from taxation, accounting, marketing and supply chain management. 